\section{MORBIDITY BOSS ASSOCIATED WITH NUTRITIONAL STATE IN CONGENITAL CARDIAC SURGERY}

\section{J.C.S. Herrera ${ }^{1}$, V.E.M. Calderón ${ }^{2}$, A.M. Treviño³ \\ ${ }^{1}$ Pediatric Oncology Unit, ${ }^{2}$ Pediatrics Unit, ${ }^{3}$ Clinical Laboratory, Mexican Social Security Institute, Cd. Obregón, Mexico}

Background and aim: Nutritional condition is a very important factor in cardiac surgery morbidity outcome. Study focused in relation among nutritional state and morbidity boss in a group of patients led to surgical correction for cardiac malformation.

Methods: Under ambispective serial cases design, we realized a study with a group of patients go cardiac surgery by congenital cardiopathy in four years. By check patients files obtained antrophometric measures and calculated mass corporal index and $Z$ value to establish nutritional condition, as well as, the boss or morbidity decided for alterations in clinical and laboratory test associated with; hypertension and renal, pulmonary, cardiac, hepatic and acid-base dysfunction.

Results. Were included 229 patients' files with an average age of 7.35 years. Predominated not complex cardiopathies (83\%) and cyanogen type (85.20\%). Nutritional state in 193 (84.30\%) patients' was normal, with morbidity incidence of $58.10 \%$. Existed difference in morbidity by hypertension on having compared nutrition state $(p=0.040)$, weight $(p=0.010), Z$ value $(p=0.001)$ and IMC $(P=0.020)$; by renal dysfunction in height $(p=0.001)$ and IMC $8 \mathrm{P}=0.000)$; hepatic dysfunction in nutritional state $(p=0.000)$ and IMC $(P=0.002)$. Also existed difference between type of cardiophaty and complexity for; hypertension $(p=0.000)$ and pulmonary $(p=0.000)$, cardiac $(p=0.000)$, hepatic $(p=0.002)$ and acid-base $(p=0.000)$ dysfunction.

Conclusions: Nutritional state of patients with congenital cardiophaty have an important role for after surgery morbidity. A better nutritional state control must be tried before surgery for adaptation to trauma metabolic response in this type of patients

Key words: congenital malformations, cardiac surgery, morbidity, nutrition state, cardiac caquexia.

\section{THE EFFECT OF TIMING OF ANTENATAL STEROIDS ON EARLY POSTNATAL BLOOD PRESSURE IN EXTREMELY LOW GESTATIONAL AGE NEWBORNS}

\section{Akita, Y. Nakamura, H. Sakai, M. Mizobuchi, S. Yoshimoto, H. Nakao \\ Department of Neonatology, Kobe Children's hospital Perinatal Center, Kobe, Japan}

Background and aims: Antenatal steroids (AS) have been associated with increased postnatal blood pressure (BP) in preterm infants. The aim of this study was to determine the association between the timing of AS and early postnatal BP in extremely low gestational age newborns (ELGANs).

Methods: 68 infants between 24 and 26 wks gestation were admitted to a single tertiary centre. 14 of those were received a complete course of AS (AS group). 27 infants who received no AS served as controls. The mean arterial BP at $6 \mathrm{~h}$ of age was used as an early postnatal BP. To assess the timing of AS, the time interval between AS administration and delivery was determined.

Results: The average mean BPs at $6 \mathrm{~h}$ of age were significantly correlated with the time intervals between AS administration and delivery in the AS group $(r=0.64, p=0.01)$. There was no significant difference in the mean BP at $6 \mathrm{~h}$ of age between the AS group and controls. Whereas, 5 infants in the AS group who received $A S \geq 96 \mathrm{~h}$ before birth showed significantly higher mean BPs at $6 \mathrm{~h}$ of age than that in 9 infants who received AS $<96$ h of age $(39.1 \pm 6.8$ vs $28.8 \pm 7.9 \mathrm{mmHg}, p=0.03)$, or in infants without AS $(39.1 \pm 6.8$ vs $33.4 \pm 4.4 \mathrm{mmHg}, p=0.02)$.

Conclusions: The early postnatal BP is positively correlated with the time interval between AS administration and delivery in ELGANs born after complete course of AS. The effect of AS on early postnatal BP is evident when AS are administered $\geq 96 \mathrm{~h}$ before delivery. 